\title{
The diversity of morphological characteristics and chemical content of Celosia cristata plantlets due to gamma ray irradiation
}

\author{
IZZATUL MUHALLILIN", SYARIFAH IIS AISYAH ${ }^{\natural \bullet, ~ D E W I ~ S U K M A ~}$ \\ Department of Agronomy and Horticulture, Faculty of Agriculture, Institut Pertanian Bogor. Jl. Raya Dramaga, Bogor 166080, West Java, Indonesia. \\ Tel: +62-251-8629353, Fax: +62-251-8629353, `email: izzalilin@gmail.com, "^syarifahiis@yahoo.com
}

Manuscript received: 2 January 2019. Revision accepted: 26 February 2019.

\begin{abstract}
Muhallilin I, Aisyah SI, Dewi Sukma D. 2019. The diversity of morphological characteristics and chemical content of Celosia cristata plantlets due to gamma ray irradiation. Biodiversitas 20:862-866. Celosia cristata L. or better known as Jengger Ayam is an ornamental plant that has a unique flower shape with attractive colors. Besides, this plant also contains antioxidants and chemical compounds that are used for traditional medicine to treat high blood pressure, and diabetes or as eye ailments. Increased diversity of $C$. cristata through hybridization techniques is constrained by flowers forming small grains that makes it difficult for castration and isolation of reproductive organs. This study aimed to increase $C$. cristata diversity of morphology and chemical content using mutation techniques induced by gamma irradiation. Plantlets were irradiated at 0, 25, 50 and 75 Gy doses. Scoring was conducted for 5 weeks until MV6 generation. Planlets were acclimatized for 3 weeks. The surviving plants were moved onto experimental land until seeded and tested for phytochemicals. Gamma irradiation with 25, 50 and $75 \mathrm{~Gy}$ doses produced 4 clones that have morphological changes in color and shape of the stem, leaves, and flowers. Changes in chemical content were observed with the appearance of triterpenoid compounds in 1 clone irradiated with $25 \mathrm{~Gy}$.
\end{abstract}

Keywords: In vitro, mutant, ornamental plant

\section{INTRODUCTION}

Celosia cristata L. or better known as Jengger Ayam is a member of the family Amaranthaceae which grows wide in South America, Africa, and Asia. This plant has a unique flower shape with variety of colors which is widely used for landscape ornamental plants, potted ornamental plants, as cut flowers and for decoration (Porat et al. 1995; Taha and Wafa 2012). The chemical content of $C$. cristata consists of antioxidants and chemical compounds such as saponins, flavonoids, and betalains, and phenol glycosides (Zhang et al. 2016). C. cristata has long been used as a traditional medicinal plant in China to treat high blood pressure, paralysis, cataracts, keratitis, diabetes, iridocyclitis, caligo corneae, and sarcoptidosis. The leaves and flowers of this plant are used as vegetables in India, West Africa, and South America. In addition, it can be used as a natural dye and has the potential as a cosmetic ingredient to prevent aging (Pyo et al. 2008; Wang et al. 2010; Sun et al. 2011; Badawi et al. 2015). Ornamental plant industry is faced with the demands of consumers to provide flowers that have added value and unique characters such as flower shape, flower color, and have a long lifespan. As a cut flower, C. cristata still encounters various obstacles including the relatively long time of flower production, which is around 4 months (Zuck 2015) and the flower color spectrum tends to be less than Chrysanthemum.

Morphological and chemical diversity of C. cristata needs to be developed continuously. Breeding $C$. cristata through hybridization is constrained in the small size of the flower which ranges from 6-8 $\mathrm{mm}$ gathered to form a set of inflorescences (Van Steenis et al. 1978), and it is selfpollinated plant (UPOV 2001). This fact makes castration and isolation of reproductive organs more complicated. Induce mutation using physical or chemical mutagens combined with in vitro culture technique is an effective method for plant improvement in several vegetative plants since it provides an opportunity to increase the variability of important economic cultivars (Bala and Kanwar 2015).

Induced mutations with gamma-ray irradiation have been widely used in plants. It can induce morphological changes in plant tissues and various biochemical changes at the cellular level to form new mutants that have new productivity potential, produce higher metabolite content and develop varieties with better economic and agronomic characteristics (Wi et al. 2007; Rahimi and Bahrani 2011). In Chrysanthemum flowers, gamma irradiation causes changes in the shape and color of flowers (Kim et al. 2016). Changes in the morphological character of plants due to gamma irradiation also occur in Polianthes tuberosa, Delphinium malabaricum, and Rosa hybrida. (Bala and Kanwar 2015; Kolar et al. 2015; Kayalvizhi et al. 2017). Changes in the chemical content of gamma-ray irradiation occur in Sesuvium portulacastrum showing an increase in the content of ecdysteroid 20-hydroxyecdysone which functions to cure muscle atrophy and as protective cosmetic ingredients against UV light, while in Sesamum indicum, there is an increase of amino acid content and fatty acids in the seeds (Hussein and Hamideldin 2015; Kapare et al. 2017). 
Previous research showed the radiosensitivity of $C$. cristata planlets $\mathrm{LD}_{50}, \mathrm{LD}_{30}$ and $\mathrm{LD}_{20}$ were $68.73,46.68$ and 35.65 Gy respectively. The Mutant response of plantlets produced in MV3 generation is abnormal growth such as shortening of internode and curly leaves (Hayati et al. 2016). The aim of this research was to obtain morphologically and chemically variants of $C$. cristata plants as a result of gamma irradiation.

\section{MATERIALS AND METHODS}

The research was conducted from August 2017 to August 2018 at the Network Culture Laboratory 1 Department of Agronomy and Horticulture, Bogor Agricultural Institute, Bogor, Indonesia and Sabisa Farm, Bogor, Indonesia. Plantlets of C. cristata consisted of buds containing 1-2 nodes with 3-5 leaves, and were planted under sterile conditions on MS media without plant growth regulators (MS0). Plantlets were irradiated at doses of 0 , 25, 50 and 75 Gy of gamma-rays at the National Nuclear Energy Agency of Indonesia, South Jakarta, Indonesia. Plant maintenance was carried out for 5 weeks for each generation then they were cultured until MV6 generation. MV6 plants were then transferred to pre-acclimatization media to strengthen the plants for 1 month before acclimatization. Prepared acclimatized $C$. cristata plantlets were planted in a closed plastic cup with some holes using sterile media in the combination of 1: 1 cocopeat and husk for 3 weeks. Weekly readings were conducted on plantlets including the number of shoots, number of leaves, number of nodes, and number of roots measured. In plants that were successfully acclimatized the reading was taken on plant height $(\mathrm{cm})$, stem diameter $(\mathrm{cm})$, number of branches, and number of flowers. To describe qualitative characters, the colors and shapes of leaves, stems, and flowers were observed following the UPOV standard for Celosia (2001) as well as the special phenotypic characters that appeared in irradiated plants. Flower colors were compared using the RHS mini color chart guide. Data is processed using Microsoft Excel and PB STAT.

Phytochemical content was analyzed based on the Harborne (1984) method to determine the presence of secondary metabolites of alkaloids, flavonoids, tannins, saponins, terpenoids, and steroids. The color of white sediment indicates the presence of alkaloids with Meyer reagents, brown deposits with Wagner reagent, and red deposits by Dragendroff reagents. The orange color with $\mathrm{Mg}^{2}+$ powder, $\mathrm{HCl}$ solution in ethanol (1: 1) and amyl alcohol solution showed the presence of flavonoids. The addition of $1 \% \mathrm{FeCl}_{3}$ to the extract gives a dark blue color indicating the presence of tannin compounds. Dissolution of samples with distilled water and heating and shaking will show the presence of saponin compounds. The sample extract with Lieberman Burchard reagent showing red or blue color indicates the presence of terpenoids, while the blue or green color indicates the presence of steroids.

\section{RESULTS AND DISCUSSION}

\section{Planlets growth until acclimatization}

Mutations induced by gamma irradiation occur randomly so that changes in an individual plant can be seen by the existence of extreme values on the graph. In the character of the number of plantlet buds, there was an extreme value at $50 \mathrm{~Gy}$ with a total of 15 shots. The character of the number of leaves in plantlets irradiated at $25 \mathrm{~Gy}$ has an extreme value of 72 leaves. The character of the number of nodes has 2 extreme values at different radiation doses. At a dose of $25 \mathrm{~Gy}$, there were 17 nodes while at a dose of 50 Gy there were only 14 nodes (Figure 1).
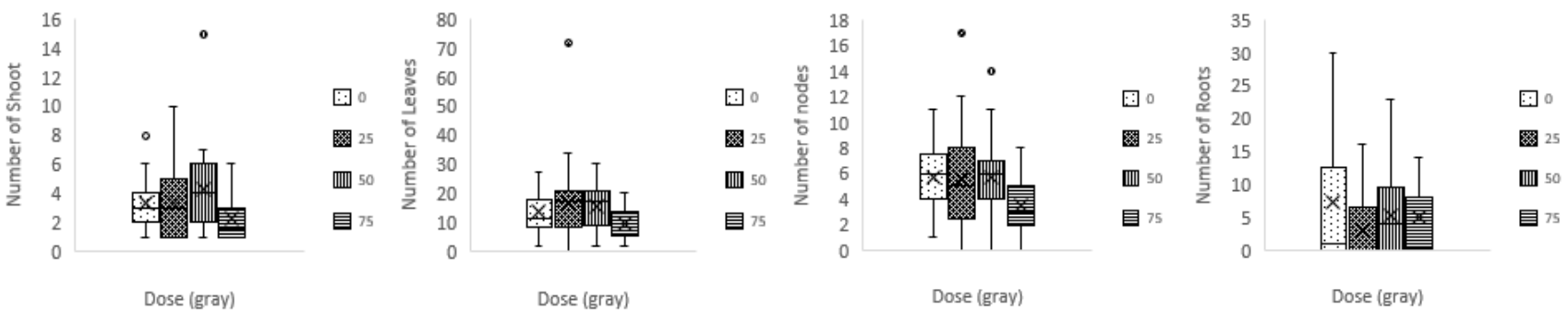

Figure 1. Boxplot of various characters on planlets in MV6 generation
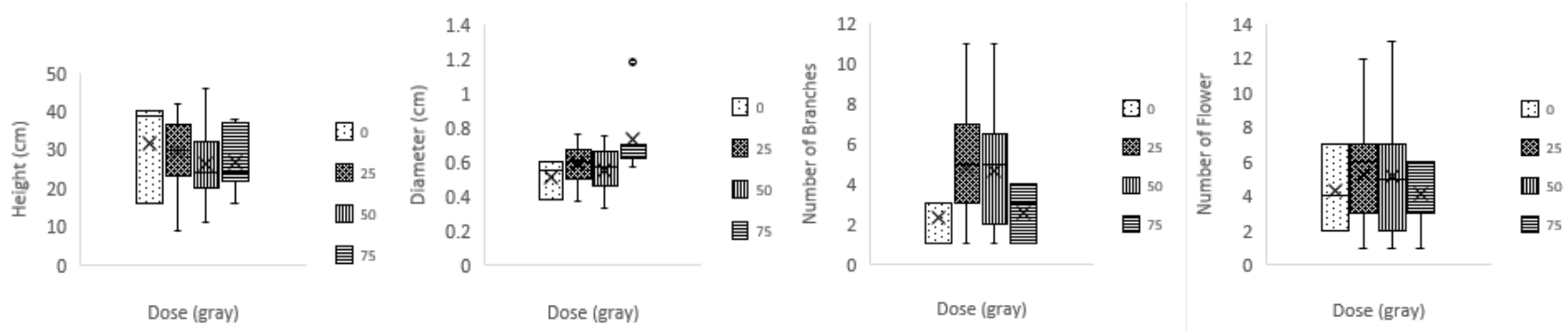

Figure 2. Boxplot of various characters on acclimatized plants 

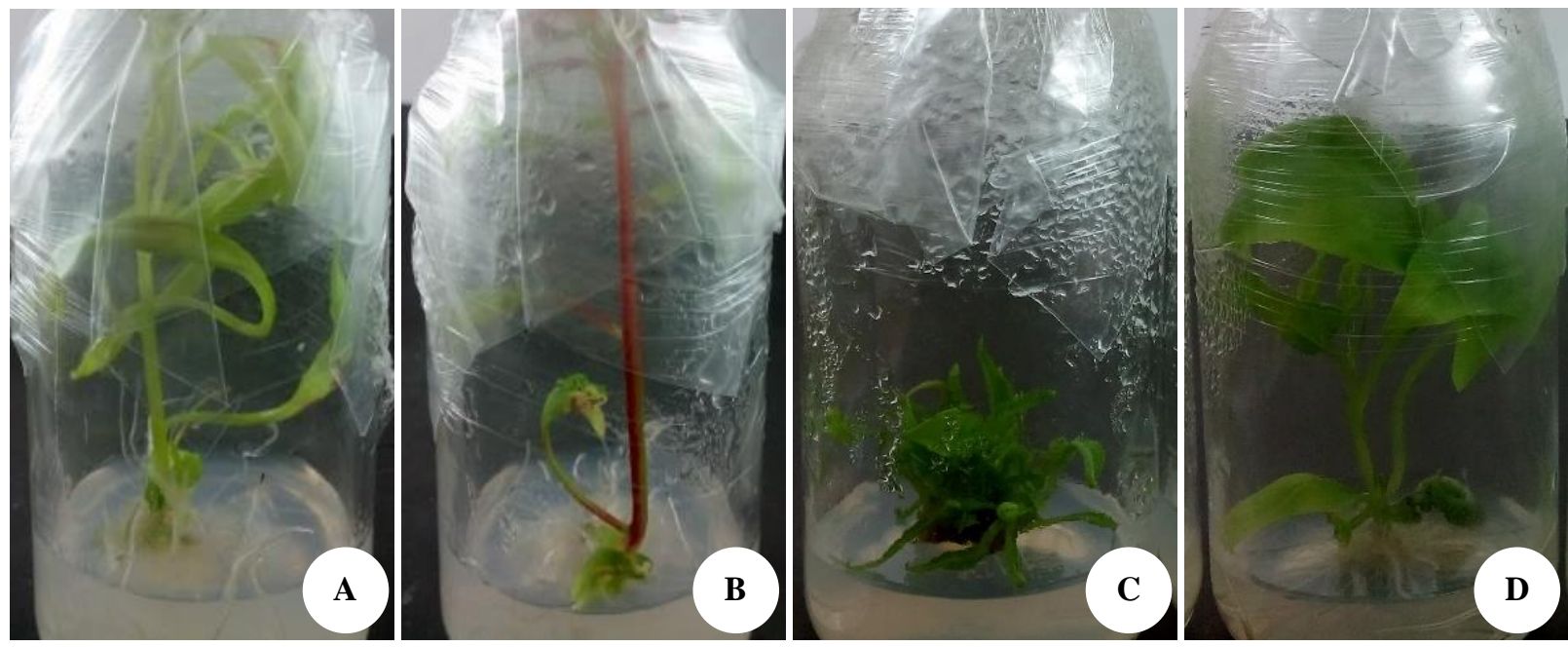

Figure 3. Morphology of plantlets in MV4 generation. A. Control planlets, B. 50 Gy mutant plantlets which had chimera, C. irradiated plants with internode shortening and crowded leaves, D. Irradiated plant leaves larger than control plants
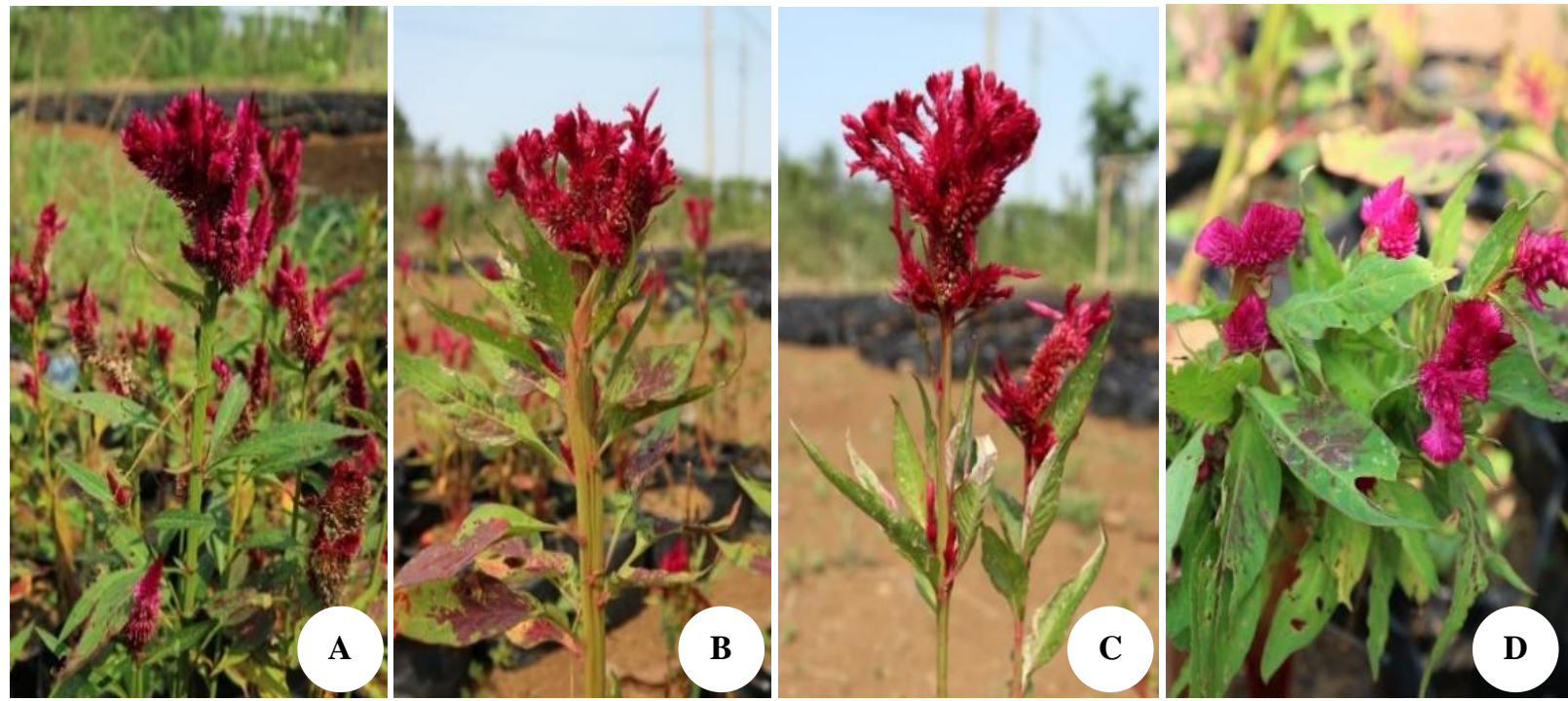

Figure 4. Successfully acclimatized control plant (A) and irradiated plants C3U2 1.3.2 (B), C1U2 5.1.1 (C), C2U1 6.1.5 (D)

After 3 weeks of acclimatization, the plants were transferred to the experimental field. Extreme values of plant clones that were successfully acclimatized were found in trunk diameter characters with a value of $1.18 \mathrm{~cm}$ in irradiated clones at 75 Gy (Figure 2). In the character of the number of roots, height, the number of branches and the number of flowers, no extreme value was found. The extreme value of the observed character has greater value than the control.

In Dianthus, there was a diplontic selection phenomenon where new mutants were formed in the MV3 generation. This mutant did not appear in next generation (Aisyah et al. 2009). Kayalvizhi (2017) reports that in the Polianthes tuberosa L. which were irradiated with gamma rays, there were leaves which were variegated in the M1V2 generation and changed in the color and number of flowers.
After 3 weeks of acclimatization, the plants were then transferred to the experimental field. The morphological characteristics of the plant were observed until the plants produced flowers and seeds. Clone C3U2 1.3.2 which was irradiated at 75 Gy showed changes in the shape of the broad stems with twisted ends and reddish colors (Figure 4.B) whereas, in control plants, there were also plants with slightly wider stems but not twisted in green and reddish in the lower part (Figure 4.A). Discoloration of stems and leaves (Figure 4.C) was indicated by the presence of white streaks on the stems and leaves (variegated). This change only occurred in C1U2 5.1.1 which was irradiated at 25 Gy. The flower of the mutant plant in Figure 4.D only formed sterile flowers. Those plants did not produce seeds (sterile). This change occurred in plants irradiated at $50 \mathrm{~Gy}$, C2U1 6.1.5. The color and shape of the flower and leaf 
color did not indicate the change. Both the control plants and the irradiated plants were reddish purple (Purple Group $71 \mathrm{~A})$ with cristate shape of flower. The color of leaves was green with purple in the main vessels of the leaves. The diversity of qualitative characteristics in plants was summarized in Table 1.

Gamma rays are one type of electromagnetic wave radiation that produces energy by releasing electrons from target cells which can cause direct damage to molecules due to the energy of radiation is absorbed by DNA molecules. Indirectly, that energy is not absorbed by DNA but with other molecules in the cell to produce free radicals which ultimately cause changes in DNA molecules. It includes damage to double strand, loss of nitrogen base and chemical changes in base structures that can change pairs of bases causing gene mutations (Chahal and Gosal 2003). This has a direct impact on living tissue because it can cause damage or changes to important components in the cell, causing changes in morphology, anatomy, biochemistry and plant physiology (Mba et al. 2011). Morphological changes in Rose's internode explants which were irradiated by gamma rays at doses of 25,40 and 55 Gy were indicated by the presence of albino leaves, variegated leaves, fused leaves and flowers with different colors were also found (Bala and Kanwar 2015).

\section{Phytochemical analysis}

Successfully acclimatized plantlets were analyzed by phytochemical tests to determine the presence of flavonoids, alkaloids, tannins, saponins, quinones, steroids and triterpenoids. In this study, phytochemical tests were carried out on 2 control plants and 3 plants at each irradiation dose (table 2). Phytochemical test resulted from control plants (K1 and K2) showed the presence of flavonoid, saponin and steroid compounds. Plant C1U3 2.3.1 shows triterpenoid content which controls did not have. That plant had been irradiated at a dose of $25 \mathrm{~Gy}$. Triterpenoids are secondary metabolites with carbon frames derived from six isoprene units and derived from $\mathrm{C}$ 30 acyclic hydrocarbons, namely squalene. These compounds are cyclic or acyclic and often have alcohol, aldehyde, or carboxylic acids (Harborne 1984). Most Triterpenoid compounds have prominent physiological activities so that in daily life, many of them are used as medicine for diabetes, menstrual disorders, snake failure, skin disorders, liver damage, and malaria. Meanwhile, for plants containing Triterpenoid compounds, there are ecological values because these compounds work as antifungus, insecticides, anti-predator, anti-bacterial and antiviral (Robinson 1995).

Table 1. Diversity of morphological characters in acclimatized C. cristata

\begin{tabular}{|c|c|c|c|c|c|}
\hline Clone & $\begin{array}{c}\text { Intensity of } \\
\text { anthocyanin coloration } \\
\text { at base } \\
\end{array}$ & $\begin{array}{l}\text { Shape in cross } \\
\text { section }\end{array}$ & Leaf shape & Shape of leaf apex & $\begin{array}{r}\text { Fertility of } \\
\text { inflorescence }\end{array}$ \\
\hline Control & Strong, medium, weak & Circular, flattened & Ovate, elliptic & Long acuminate & Fertile \\
\hline C1U2 5 & Strong, medium & Circular, flattened & Ovate, elliptic & Long acuminate & Fertile, sterile \\
\hline C1U3 4 & Strong & Circular, flattened & Ovate, elliptic & Long acuminate & Fertile \\
\hline C1U3 2 & Strong, medium & Circular & Ovate, elliptic & Long acuminate & Fertile \\
\hline C1U5 5 & Medium, weak & Circular & Ovate, elliptic & Long acuminate & Fertile \\
\hline C1U2 3 & Strong & Flattened & Ovate & Long Acuminate & Fertile \\
\hline C2U1 2 & Strong, medium & Circular & Ovate, elliptic & Long acuminate & Fertile, sterile \\
\hline C2U1 5 & Strong, medium, weak & Circular, flattened & Ovate, elliptic & Long acuminate & Fertile \\
\hline C2U1 6 & Strong, medium, weak & Circular & Ovate, elliptic & Long acuminate & Fertile \\
\hline $\mathrm{C} 2 \mathrm{U} 24$ & Strong, medium & Circular, flattened & Ovate, elliptic & Long acuminate & Fertile \\
\hline C3U1 3 & Strong, medium & Circular, flattened & Ovate, elliptic & Long acuminate, short acuminate & Fertile \\
\hline C3U2 1 & Strong, medium & Circular, flattened & Ovate, elliptic & Long acuminate, short acuminate & Fertile \\
\hline
\end{tabular}

Table 2. Test results of phytochemical compounds on C. Cristata

\begin{tabular}{|c|c|c|c|c|c|c|c|}
\hline Clone & Dose (Gy) & Flavonoid & Alkaloid & Tanin & Saponin & Steroid & Triterpenoid \\
\hline K1 & 0 & + & - & - & + & + & - \\
\hline $\mathrm{K} 2$ & 0 & + & - & - & + & + & - \\
\hline C1U2 5.1.1 & 25 & + & - & - & + & + & - \\
\hline C1U5 5.4.1 & 25 & + & - & - & + & + & - \\
\hline C1U3 2.3.1 & 25 & + & - & - & + & + & + \\
\hline C2U2 4.1.1 & 50 & + & - & - & + & + & - \\
\hline C2U1 6.9.1 & 50 & + & - & - & + & + & - \\
\hline C2U1 2.1.1 & 50 & + & - & - & + & + & - \\
\hline C3U2 1.3.2 & 75 & + & - & - & + & + & - \\
\hline C3U2 1.3.1 & 75 & + & - & - & + & + & - \\
\hline C3U1 3.1.1 & 75 & + & - & - & + & + & - \\
\hline
\end{tabular}

Note:-= not identified, $+=$ identified 
Gamma irradiation has energy that is able to change the atomic structure to ionize so that it directly affects the tissues (Mba et al. 2011). The response of ionizing is production of reactive oxygen species (ROS) as radiolysis of cellular water. These ROS are reported as free radicals that play an important role during plant defense responses and induce changes in plant (Esnault et al. 2010; Moghaddam et al. 2011). These changes include cellular structure and metabolic processes such as enlargement of the thylakoid membrane, photosynthetic changes, modulation antioxidant systems and accumulation of phenol compounds (Kovács and Keresztes 2002; Wi et al. 2007). The study of Ramabulana et al. (2015) reported the presence of the chalcone, phloretin-3',5'-di-C- $\beta$ glycopyranosyl in Phaseolus vulgaris which were irradiated by gamma rays so that gamma radiation has a function against oxidative stress.

Irradiation with doses of $0,25,50$ and 75 Gy on $C$. cristata plantlets on MV6 generation showed changes in morphological characters in the stem, leaves, and flowers. These changes occurred in 4 plants. Changes in chemical content occurred in clone C1U3 2.3.1 that irradiated at 25 Gy. Change in chemical content was indicated by the triterpenoid content.

\section{ACKNOWLEDGEMENTS}

The author would like to thank Bogor Agricultural University, Indonesia and Indonesia Endowment Fund for Education, Ministry of Finance, the Republic of Indonesia for the financial support and facilities provided in this study.

\section{REFERENCES}

Aisyah SI, Aswidinoor H, Saefudin A, Marwoto B, Sastrosumarjo S. 2009. Induksi mutase pada pucuk Anyelir (Dianthus caryophyllus Linn.) melalui iradiasi sinar gamma. J Agron Indonesia 37 (1): 62-70. [Indonesian]

Baig MMQ, Hafiz I A, Abbasi NA, Ahmad T. 2015. Evaluating and validating the protocol for gamma $(\gamma)$ radiation-induced mutations in floral distinct Rosa spp. Pak J Bot 47 (5): 1847-1854

Bala M, Kanwar PS. 2015. In vitro mutagenesis in rose (Rosa hybrida L.) cv. Raktima for novel traits. Indian J Biotech 14: 525-531

Chahal GS, Gosal SS. 2003. Principles and Procedure of Plant Breeding. Narosa Publishing House, Delhi

Esnault M, Legue F, Chenal C. 2010. Ionizing radiation: advances in plant response. Environ Exp Bot 68: 231-237

Harborne JB. 1984. Phytochemical Methods. A Guide to Modern Techniques of Plant Analysis. 2nd ed. Chapman and Hall, London.

Hayati D, Syarifah IA, Krisatini. 2016. Radiosensitivity levels of in vitro cultured Celosia cristata planlets by $\gamma$-ray irradiation. J Trop Crop Sci 3 (2): 61-65.
Hussein OS, Hamideldin N. 2015. Influence of pre-sowing treatments by gamma rays on growth, yield and some chemical constituents of Sesamum indicum L. Grasas Aceites 67 (1):1-6

Jan S, Parween T, Siddiqi TO, Mahmooduzzafar. 2012. Effect of gamma radiation on morphological, biochemical, and physiological aspects of plants and plant products (Review). Environ Rev 20: 17-39.

Kapare V, Satdive R, Fulzele DP, Malpathak N. 2017. Impact of gamma irradiation induced variation in cell growth and phytoecdysteroid production in Sesuvium portulacastrum. J Plant Growth Regul 1-12

Kayalvizhi K, Kannan M, Ganga M. 2017. Effect of physical and chemical mutagens on morphological characters in M1V2 Generation of Tuberose (Polianthes tuberosa L.). Intl J Curr Microbiol App Sci 6 (4): 2492-2499.

Kim YS, Sung SY, Jo YD, Lee HJ, Kim SH. 2016. Effects of Gamma Ray dose rate and sucrose treatment on mutation Induction in Chrysanthemum. Eur J Hortic Sci 81 (4): 212-218.

Kolar FR, Ghatge SR, Nimbalkar MS, Dixit GB. 2015. Mutational changes in Delphinium malabaricum (Huth.) Munz: A potential ornamental plant. J Hortic Res 23 (2): 5-15.

Kovács E, Keresztes Á. 2002. Effect of gamma and UV-B/C radiation on plants cells. Micron 33: 199-210.

Mba C, Afza R, Shu QY. 2011. Mutagenic Radiations: X-Rays, Ionizing particles and Ultraviolet. In: IAEA Plant Mutation Breeding and Biotechnology. Electronic Publishing Policy and Support Branch Communication Division FAO, Rome, Italy.

Moghaddam SS, Jaafar H, Ibrahim R, Rahmat A, Aziz MA, Philip E. 2011. Effect of acute gamma irradiation on physiological traits and flavonoid accumulation of Centella asiatica. Molecules 16: 49945007.

Porat R, Shlomo E, Halev AH. 1995. Horticultural techniques to improve Celosia plumosa growth for cut flowers. Scientia Holticulturae 63: 209-214.

Pyo YH, Yoon MY, Son JY, Choe TB. 2008. The effect of Celosia cristata $\mathrm{L}$. ethanol extract on anti-oxidant and anti-aging activity. Korean J Biotechnol Bioeng 23 (5): 431-438.

Rahimi MM, Bahrani A. 2011. Effect of gamma irradiation on qualitative and quantitative characteristics of canola (Brassica napus L.). Middle-East J Sci Res 8 (2): 519-525.

Ramabulana T, Mavunda RD, Steenkamp PA, Piater LA, Dubery IA, Madala NE. 2015. Secondary metabolite perturbations in Phaseolus vulgaris leaves due to gamma radiation. Plant Physi and Biochem 97: 287-295.

Robinson T. 1995. Kandungan Organik Tumbuhan Tinggi. Institut Teknologi Bandung, Bandung. [Indonesian]

Sun ZL, Gao GL, Xia YF, Qiao ZY. 2011. A new hepoprotective saponin from semen Celosia cristata. Fitoterapia 82: 591-594.

Taha RM, Wafa SN. 2012. Plant regeneration and cellular behaviour studies in Celosia cristata grown in vivo and in vitro. Sci World J 2012: 359413. DOI: 10.1100/2012/359413.

UPOV. 2001. Draft guideline for the conduct of test for distinctness, uniformity, and stability; Celosia: Celosia L. Intl. Union for The Protection of New Varieties of Plants, Geneva.

Van Steenis CGGJ, Bloembergen S, Eyma PJ. 1978. Flora. PT. Pradnya Paramita, Jakarta

Wang Y, Lou Z, Wu QB, Guo ML. 2010. A novel hepatoprotective saponin from Celosia cristata L. Fitoterapia 81: 1246-1252.

Wi SG, Chung BY, Kim JS, Kim JH, Baek MH, Lee JW, Kim YS. 2007. Review: Effect of gamma irradiation on morphological changes and biological responses in plants. Micron 38: 553-564.

Zhang SM, Wang XF, Feng J, Sun ZL. 2016. Chemical constituent of the seeds of Celosia cristata. Chemi Nat Comp 52 (5): 827-829. 